\title{
Improvement of paranoid schizophrenia coincides with reduction of testosterone substitution of hypogonadotropic hypogonadism
}

\author{
J Deckert, HC Estler, KP Lesch \\ Department of Psychiatry, University of Würzburg, Füchsleinstr 15, 87 Würzburg, Germany \\ (Received 15 February 1993; accepted 19 February 1993)
}

Testosterone substitution is routinely performed in patients with hypogonadotropic hypogonadism, $e g$ patients with Klinefelter syndrome, a sex chromosome disorder $(47, \mathrm{xxy})$ with a frequency of 1:500 men (eg Wilson and Griffin, 1987). Patients with this disorder are known to have a 3 -fold increased life-time risk to develop some form of schizophrenia (Propping and Friedl, 1988).

We report a case of paranoid schizophrenia and concomitant hypogonadotropic hypogonadism.

Mr HF, a 27 year-old bachelor was born in 1965 after eight months of pregnancy. He had to be supported in a pediatric intensive care unit. Between the age of 4 and 21 he was treated with gonadotropins because of cryptorchism and pubertas tarda. He underwent orchidopexia in 1973. Hypogonadotropic hypogonadism was diagnosed in 1980. Testosterone substitution was initiated in 1986. In 1989 he first experienced a schizophrenic episode with predominantly paranoid and hallucinatory symptoms. He continued to suffer from lack of initiative, attention deficit and stress intolerance and developed a delusion system. In the following years he had to be admitted yearly due to exacerbations of his schizophrenic psychosis associated with hostile behaviour. On July 301992 he was admitted again in a euphoric mood with grandiose ideation in the context of his delusion system, accompanied by verbal hallucinations. He did not feel sick and had to be treated on the basis of a judicial order. Physical examination showed small testes and little virile hair growth. A $46 \mathrm{XY}$ caryotype was found. Cranial MRI, CT and EEG were normal with the exception of a slight, asymmetric ventricular enlargement. During the follow- ing nine weeks, high-dose neuroleptic treatment with haloperidol up to $30 \mathrm{mg} /$ day or fluphenazine up to $18 \mathrm{mg} /$ day po accompanied by administration of fluphenazine-decanoate up to $75 \mathrm{mg}$ and testosterone $250 \mathrm{mg}$ im every two weeks, had no effect on the psychotic symptomatology. Testosterone levels approximately one week after substitution were at the upper normal concentration range with $10.4 \mathrm{ng} / \mathrm{ml}(3-12 \mathrm{ng} / \mathrm{ml})$ and after three weeks were still at $5.2 \mathrm{ng} / \mathrm{ml}$. Prolactin levels were increased with $39.9 \mathrm{ng} / \mathrm{ml}(1.2-8.8 \mathrm{ng} / \mathrm{ml})$. FSH with $0.5 \mathrm{mI} \mu / \mathrm{ml}(1-14 \mathrm{mI} \mu / \mathrm{ml})$ and $\mathrm{LH}$ with less than $0.5 \mathrm{mI} \mu / \mathrm{ml}(1.5-9.2 \mathrm{mI} \mu / \mathrm{ml})$ were decreased, while estradiol, progesterone and dehydroepiandrostenone were in the normal range. The consulting andrologist recommended cessation of testosterone substitution for evaluation of its necessity. The patient, however agreed only to a four-week interval between administrations. Testosterone levels one week after administration were $5.2 \mathrm{ng} / \mathrm{ml}$. In the following 11 weeks, during continuation of the neuroleptic treatment, the patient gradually improved. Apparently, the intensity of his psychotic experience decreased. While his delusion system was still present, he was less hostile and consequently became less autistic and socially more competent. He consented to treatment and was finally released after 20 weeks.

Anabolic-androgenic hormones were originally developed as drugs to increase aggressiveness and testosterone has been suggested to provoke psychotic symptoms in vulnerable individuals (Williamson and Young, 1992). On the other hand, a delaying effect of estradiol on the onset of schizophrenia has been suggested (Häfner et al, 1992). While the im- 
provement of the psychotic symptoms and in particular, of hostility, may well be due to several reasons such as spontaneous improvement or delayed antipsychotic effect of the applied neuroleptics, it coincided with the reduced testosterone administration.

We therefore suggest to consider a reduction or temporary cessation of testosterone substitution in patients with hypogonadotropic hypogonadism who suffer from neuroleptic-resistant schizophrenia.

\section{References}

Häfner H, Riecher-Rössler A, Maurer K, Fätkenheuer B, Löffler W (1992) First onset and early sympto- matology of schizophrenia. A chapter of epidemiological and neurobiological research into age and sex differences. Psychiatry Clin Neurosci 242, $109-118$

Propping P, Friedl W (1988) Genetic studies of biochemical, pathophysiological and pharmacological factors in schizophrenia. In: Handbook of Schizophrenia, vol 3 (Tsuang MT, Simpson JC, eds). Elsevier, Amsterdam, 579-608

Williamson DJ, Young AH (1992) Psychiatric effects of androgenic and anabolic androgenic steroid abuse in men: a brief review of the literature. $J$ Psychopharmacol 6, 20-26

Wilson JD, Griffin JE (1987) Disorders of sexual disorientation. In: Harrison's Principles of Internal Medicine (Braunwald E, Isselbacher KJ, Petersdorf RG, Wilson JD, Martin JB, Fauci AS, eds). McGraw-Hill, New York, $1840-1853$ 